\title{
Robert Estienne, Traicté de la Grammaire Francoise (1557).
}

Édition commentée par Colette Demaizière. Paris : Honoré Champion, 2003, 202 p., collection Textes de la Renaissance 75.

Maria Colombo Timelli

\section{(2) OpenEdition}

\section{Journals}

Édition électronique

URL : https://journals.openedition.org/dhfles/1274

DOI : $10.4000 /$ dhfles. 1274

ISSN : 2221-4038

Éditeur

Société Internationale pour l'Histoire du Français Langue Étrangère ou Seconde

Édition imprimée

Date de publication : 1 juin 2004

Pagination : 163-165

ISSN : 0992-7654

Référence électronique

Maria Colombo Timelli, « Robert Estienne, Traicté de la Grammaire Francoise (1557). », Documents pour I'histoire du français langue étrangère ou seconde [En ligne], 32 | 2004, mis en ligne le 01 janvier 2012, consulté le 27 mai 2021. URL : http://journals.openedition.org/dhfles/1274 ; DOI : https://doi.org/ $10.4000 /$ dhfles. 1274

Ce document a été généré automatiquement le 27 mai 2021.

(c) SIHFLES 


\title{
Robert Estienne, Traicté de la Grammaire Francoise (1557).
}

Édition commentée par Colette Demaizière. Paris : Honoré Champion, 2003, 202 p., collection Textes de la Renaissance 75.

\author{
Maria Colombo Timelli
}

1 La collection « Textes de la Renaissance », série « Traités sur la langue française ", met à la disposition des chercheurs, depuis quelques années, des traités du plus haut intérêt dans le domaine de la linguistique française du XVIe siècle, que ce soit sous une forme bilingue (latin/français pour la Grammaire de Cauchie/Caucius, anglais/français pour L'éclaircissement de Palsgrave) ou sous leur forme originale commentée comme c'est le cas ici.

2 L'étendue et l'importance de l'activité de Robert I ${ }^{\mathrm{er}}$ Estienne, imprimeur, lexicographe, philologue, linguiste, grammairien, ne sont plus à souligner. Colette Demaizière retrace rapidement sa biographie en mettant en relief, à côté d'une production mieux connue et certainement plus remarquable, celle liée à la lexicographie mono- et bilingue, l'œuvre pédagogique, dont la valeur n'avait pourtant pas échappé à ses contemporains,puisque Daurat lui-même l'avait célébrée dans des vers latins demeurés célèbres. En effet, les ouvrages didactiques, destinés pour l'essentiel à l'enseignement/ apprentissage du latin, occupèrent les presses de Robert Estienne, aussi bien à Paris qu'à Genève, pendant au moins trente ans, jusqu'à la fin de sa vie. Le succès de ces manuels fut durable et continu: la Maniere de tourner en langue francoise les verbes fut imprimée vingt années durant, de 1526 à 1547, le De Gallica verborum declinatione et La maniere de tourner toutes especes de noms latins en nostre langue Francoyse en 1540, Les mots Francois tournez en latin en 1544, un recueil de traités pédagogiques (dont l'Ars minor de Donat en version bilingue) à partir de 1546 ; et même après la mort de leur auteur, ils continuèrent d'être imprimés et vendus par ses descendants. Il faut encore souligner, outre la continuité de cette production, son double aspect, grammatical et lexicographique, avec une égale attention pour la langue classique et pour le français, ce qui n'était pas la règle au siècle de la Renaissance. La métalangue de ces traités alterne aussi, en fonction du sujet mais surtout du public envisagé : Robert Estienne 
adoptait le français pour enseigner le latin à ses compatriotes, le latin pour enseigner sa propre langue maternelle aux étrangers.

3 C'est l'année même de sa mort qu'il publia son Traicté, sans indication de lieu (Genève) et sans date (mais elle est donnée à l'intérieur du texte: 1557). L'ouvrage connut d'autres éditions, en latin à partir de 1558 (la traduction était due à Henri, fils de Robert), et des réimpressions dans sa forme originale jusqu'en 1582. Colette Demaizière présente le contenu du manuel en nuançant tout particulièrement les jugements sévères portés par Brandon et par Brunot: Robert Estienne ne cache pas que le Traicté de la Grammaire Francoise est une compilation de Sylvius/Dubois (Isagoge, 1531) et de Meigret (Tretté de la Grammere francoeze, 1550), qu'il a complétés par le recours à d'autres sources; il a cependant réorganisé ce matériel à la manière des grammaires latines, selon l'unique modèle existant à son époque. C'est alors en véritable novateur qu'il ose rompre le nombre canonique des huit parties du discours pour reconnaître à l'article sa propre autonomie et la place qui lui revient, aussi bien dans la phrase française que dans un manuel de grammaire. La morphologie donatienne, ses classements, ses définitions, son lexique, demeurent néanmoins reconnaissables à chaque page du texte ; le latin est surtout présent, et il pèse de tout son poids, dans la seconde partie du Traicté, consacrée à la Mutation des lettres des mots Latins faicts Francois, sorte de petit ouvrage autonome visant à présenter méthodiquement - en suivant l'ordre alphabétique - les changements graphiques survenus lors du passage du latin au français. Les Sihflésiens y reconnaîtront sans peine le modèle de tant de petits traités bilingues des XVII ${ }^{e}$ et XVIII ${ }^{\mathrm{e}}$ siècles montrant la parenté entre le français, ses formes, ses terminaisons, et la langue maternelle des élèves.

Colette Demaizière offre une édition du texte (p. 27-163 : on regrette que dans les titres courants la graphie de l'intitulé soit modernisée en Traité de la grammaire française) quelque peu hybride, avec conservation de la ponctuation et des majuscules de l'original, mais avec distinction des lettres ramistes et résolution des abréviations (sauf dans les exemples, où la graphie originale est maintenue); de même, la séparation des mots agglutinés ne concerne que les cas d'ambiguïtés. Le texte qui nous est présenté n'est plus, en somme, celui de Robert Estienne, sans être celui qu'aurait proposé, avec un peu plus d'audace, un éditeur critique. L'apparat en bas de page contient en même temps des remarques sur les modifications introduites dans les éditions successives à 1557, des comparaisons avec l'édition en latin de 1582 (dernière en date), des commentaires (notamment des renvois à Sylvius, Meigret, et aux grammairiens anciens: Priscien, Quintilien, Diomède, Tertullien), des références bibliographiques (sont rappelées les études fondamentales de Flûtre 1970, Gougenheim 1974, et plus récemment Colombat 1999, textes qui, malheureusement, ne sont pas indiqués en bibliographie). En complément, deux annexes : les mots donnés en exemple dans le Traicté (p. 169-195), et la terminologie linguistique (à l'exception des mots trop fréquents : p. 197-200).

Dans le projet pédagogique de Robert Estienne tout se tient: l'œuvre lexicographique n'est point séparée des traités didactiques, consacrés au latin ou au français ; c'est sans doute ce qui fait une partie de son intérêt et qui justifie la reprise, on pourrait dire la redécouverte, de sa Grammaire. 


\section{AUTEUR}

MARIA COLOMBO TIMELLI

Università degli Studi di Milano 